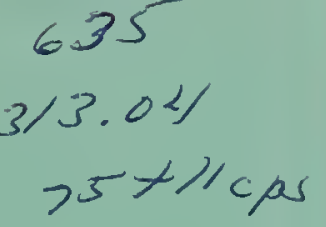

NBSIR 76-1010

\title{
Optical Materials Characterization
}

Albert Feldman, Deane Horowitz and Roy M. Waxler

Inorganic Materials Division

Institute for Materials Research

and

Irving H. Malitson and Marilyn J. Dodge

Optical Physics Division

Institute for Basic Standards

National Bureau of Standards

Washington, D. C. 20234

February 1976

Semi-Annual Technical Report

Period Covered: August 1, 1975 to January 31, 1976

ARPA Order No. 2620

Prepared for

Advanced Research Projects Agency

Arlington, Virginia 22209 



\section{OPTICAL MATERIALS CHARACTERIZATION}

Albert Feldman, Deane Horowitz and Roy M. Waxler

Inorganic Materials Division

Institute for Materials Research

and

Irving $\mathrm{H}$. Malitson and Marilyn J. Dodge

Optical Physics Division

Institute for Basic Standards

National Bureau of Standards

Washington, D. C. 20234

February 1976

Semi-Annual Technical Report

Period Covered: August 1, 1975 to January 31, 1976

ARPA Order No. 2620

Prepared for

Advanced Research Projects Agency

Arlington, Virginia 22209

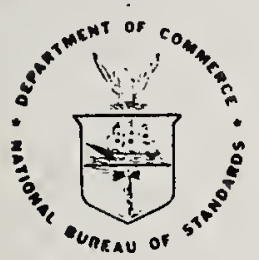

U.S. DEPARTMENT OF COMMERCE, Elliot L. Richardson, Socretery James A. Baker, III, Under Secretary

Dr. Betsy Ancker-Johnson, Assistant Secretary for Science and Technology

NATIONAL BUREAU OF STANDARDS, Ernest Ambler, Acting Director 

Albert Feldman, Deane Horowitz and Roy M. Waxler

\author{
Inorganic Materials Division \\ Institute for Materials Research \\ and \\ Irving $\mathrm{H}$. Malitson and Marilyn J. Dodge \\ Optical Physics Division \\ Institute for Basic Standards
}

\begin{abstract}
ARPA Order No. . . . . . . . . . . . . 2620
Program Code Number. . . . . . . . . . . 4D10

Effective Date of Contract . . . . . . . . . January 1, 1974

Contract Expiration Date . . . . . . . . . December 31, 1976

Principal Investigator . . . . . . . . . Albert Feldman (301) 921-2840
\end{abstract}

The views and conclusions contained in this document are those of the authors and should not be interpreted as necessarily representing the official policies, either express or implied, of the Advanced Research Projects Agency or the U. S. Government. 
Abstract

Refractive index and the photoelastic constants have been measured on specimens of reactive atmosphere processed (RAP) $\mathrm{KCl}$ and $\mathrm{KCl}$ nominally doped with $18 \mathrm{KI}$. The refractive indices were measured by the minimum deviation method in the wavelength range $0.25 \mu \mathrm{m}$ to $15.5 \mu \mathrm{m}$. Measurements were made near $20{ }^{\circ} \mathrm{C}$ and near $34{ }^{\circ} \mathrm{C}$ on the RAP specimen and near $20^{\circ}$ on the doped specimen. Each set of experimental data was fitted to a three term Sellmeier-type dispersion equation. The temperature coefficient of index was then computed for the RAP KCl. The data for the different types of $\mathrm{KCl}$ were compared to each other and to earlier reported data on commercial $\mathrm{KCl}$. The piezo-optical constants $\mathrm{q}_{11}, \mathrm{q}_{12}$ and $\mathrm{q}_{44}$ and the elasto-optical constants $\mathrm{p}_{11}, \mathrm{p}_{12}$ and $\mathrm{p}_{44}$ were obtained at $10.6 \mu \mathrm{m}$ for the RAP and doped $\mathrm{KCl}$. The measurements required the use of a modified Twyman-Green interferometer capable of measuring fringe shifts $\tau .002$ of a wave. Within experimental error the coefficients of the two materials agree. Negligible dispersion was found for $\mathrm{q}_{11}, \mathrm{q}_{12}, \mathrm{p}_{11}$ and $\mathrm{p}_{12}$ between the visible and 10.6 $\mu \mathrm{m}$ while a small dispersion was found for $\mathrm{q}_{44}$ and $\mathrm{p}_{44}$. 
1. Technical Report Summary. . . . . . . . . . . . . . . . . . . 1

1.1 Technical Problem . . . . . . . . . . . . . . . . . . . 1

1.2 General Methodology. . . . . . . . . . . . . . . . . . . 1

1.3 Technical Results. . . . . . . . . . . . . . . . . . 2

1.4 Department of Defense Implications . . . . . . . . . . . . . . . . 2

1.5 Implications for Further Research. . . . . . . . . . . . . . . 2

2. Technical Report. . . . . . . . . . . . . . . . . . . 3

2.1 Refractive Index of Reactive Atmosphere Processed (RAP)

Potassium Chloride and Potassium Chloride Doped with

Potassium Iodide - Marilyn J. Dodge and Irving H. Malitson . . . 3

2.1.1 Introduction. . . . . . . . . . . . . . . . . . 3

2.1.2 Experimental Technique. . . . . . . . . . . . . . . 3

2.1.3 Index Data. . . . . . . . . . . . . . . . . . 4

2.1.4 Temperature Coefficient of Index. . . . . . . . . . . . 6

2.1 .5 Conclusions . . . . . . . . . . . . . . . . . 8

2.1.6 Acknowledgement . . . . . . . . . . . . . . . 8

2.1 .7 References. . . . . . . . . . . . . . . . . . . 9

2.2 Photoelastic Constants of Reactive Atmosphere Processed (RAP) Potassium Chloride and Potassium Chloride Doped with Potassium Iodide - Albert Feldman, Deane Horowitz and Roy M. Waxler. . . . 10

2.2.1 Introduction. . . . . . . . . . . . . . . . . 10

2.2.2 Discussion. . . . . . . . . . . . . . . . . 10

2.2.3 Results . . . . . . . . . . . . . . . . 12

2.2.4 Acknowledgement . . . . . . . . . . . . . . . 13

2.2.5 References. . . . . . . . . . . . . . . . . 13

3. Appendix - Specimen Specifications for Photoelasticity, dn/dT, Thermal Expansion and Refractive Index Measurements. . . . . . . 17 



\section{Technical Report Summary}

\subsection{Technical Problem}

Windows subjected to high-average-power laser radiation will undergo optical and mechanical distortion due to absorptive heating. If the distortion becomes sufficiently severe, the windows become unusable. Theoretical calculations of optical distortion in laser windows depend on the following material parameters: absorption coefficient, refractive index, change of index with temperature, thermal expansion coefficient, stress-optical constants, elastic compliances, specific heat, thermal conductivity and density. Our program has been established to measure refractive indices, changes of index with temperature, stress-optical constants, elastic compliances, and thermal expansion coefficients of candidate infrared laser window materials.

\subsection{General Methodology}

Laboratory experiments are conducted for measuring refractive indices, changes of index with temperature, stress-optical constants, elastic compliances, and thermal expansion coefficients.

The refractive indices of prismatic specimens are measured on precision spectrometers by using the method of minimum deviation. Two spectrometers are used. One instrument, which uses glass optics, is used for measuring refractive indices in the visible with an accuracy of several parts in $10^{6}$. The other instrument, which uses mirror optics, is used for measuring refractive indices in the ultraviolet and the infrared to an accuracy of several parts in $10^{5}$. Using both spectrometers we can measure refractive indices over the spectral region $0.2 \mu \mathrm{m}$ to $50 \mu \mathrm{m}$.

We measure the coefficient of linear thermal expansion, $\alpha$, by a method of Fizeau interferometry. The interferometer consists of a specially prepared specimen which separates two flat plates. Interference fringes are observed due to reflections from the plate surfaces in contact with the sfecimen. We obtain $\alpha$ by measuring the shift of these interference fringes as a function of temperature.

The change of refractive index with temperature, $\mathrm{dn} / \mathrm{dT}$, is measured by two methods. In the first method, we measure the refractive index with the precision spectrometers at two temperatures, $20{ }^{\circ} \mathrm{C}$ and $30{ }^{\circ} \mathrm{C}$, by varying the temperature of the laboratory. This provides us with a measure of $\mathrm{dn} / \mathrm{dT}$ at room temperature. The second method may be used for measuring $\mathrm{dn} / \mathrm{dT}$ up to a temperature of $800^{\circ} \mathrm{C}$. We obtain $\mathrm{dn} / \mathrm{dT}$ from a knowledge of the expansion coefficient and by measuring the shift of Fizeau fringes in a heated specimen as a function of temperature. The Fizeau fringes are due to interferences between reflections from the front and back surfaces of the specimens.

We measure stress-optical coefficients and elastic compliances using a combination of Twyman-Green and Fizeau interferometers. From the shift of fringes in specimens subjected to uniaxial or hydrostatic compression, we obtain the necessary data for determining all the stress-optical constants and 
elastic compliances. In materials with small stress-optical constants or in materials that cannot withstand large stress, we measure the stress-optical effect with a modified Twyman-Green interferometer, which has a sensitivity of less than $0.01 \lambda$ at $10.6 \mathrm{~mm}$. In this case we must know the elastic constants of the material in order to calculate the stress-optical constants.

\subsection{Technical Results}

Refractive index and the photoelastic constants have been measured on specimens of reactive atmosphere processed (RAP) $\mathrm{KCl}$ and $\mathrm{KCl}$ nominally doped with $1 \% \mathrm{KI}$. The refractive indices were measured by the minimum deviation method in the wavelength range $0.25 \mu \mathrm{m}$ to $15.5 \mu \mathrm{m}$. Measurements were made near $20{ }^{\circ} \mathrm{C}$ and near $34^{\circ} \mathrm{C}$ on the RAP specimen and near $20^{\circ}$ on the doped specimen. Each set of experimental data was fitted to a three term Sellmeier-type dispersion equation. The temperature coefficient of index was then computed for the RAP $\mathrm{KCl}$. The data for the different types of $\mathrm{KCl}$ were compared to each other and to earlier reported data on commercial $\mathrm{KCl}$. (Section 2.1).

The piezo-optical constants $q_{11}, q_{12}$ and $q_{44}$ and the elasto-optical constants $\mathrm{p}_{11}, \mathrm{p}_{12}$ and $\mathrm{p}_{44}$ were obtained at $10.6 \mu \mathrm{m}$ for the RAP and doped $\mathrm{KCl}$. The measurements required the use of a modified Twyman-Green interferometer capable of measuring fringe shifts $\sim .002$ of a wave. Within experimental error the coefficients of the two materials agree. Negligible dispersion was found for $q_{11}, q_{12}, p_{11}$ and $p_{12}$ between the visible and 10.6 $\mathrm{\mu m}$ while a small dispersion was found for $\mathrm{q}_{44}$ and $\mathrm{p}_{44}$ (Section 2.2).

\subsection{Department of Defense Implications}

The Department of Defense is currently constructing high-power infrared laser systems. Criteria are needed for determining the suitability of different materials for use as windows in these systems. The measurements we are performing provide data that laser system designers can use for determining the optical performance of candidate window materials.

\subsection{Implications for Further Research}

Measurements of refractive index, change of index with temperature, thermal expansion, stress-optical constants and elastic compliances will be continued on candidate laser window materials. The wavelength of interest will shift from $10.6 \mu \mathrm{m}$ to $3.39 \mu \mathrm{m}$, which is within the wavelength range of interest to designers of chemical laser systems ( $3-5 \mu \mathrm{m}$ range).

Apparatus is being procured and assembly of equipment is currently underway for the interferometric measurement of photoelastic constants and $\mathrm{dn} / \mathrm{dT}$. A temperature control system is being planned for interferometric measurement of $\mathrm{dn} / \mathrm{dT}$ to cover at a minimum the temperature range $-100{ }^{\circ} \mathrm{C}$ to $+100{ }^{\circ} \mathrm{C}$ which includes the temperatures of interest to military system designers.

We are currently awaiting shipment of specimens under the Laser Window Validation Program. A list of specifications has been sent to Dr. James Stanford at the Naval Weapons Center at China Lake. These specifications are included as an Appendix (Section 3.). 


\section{Technical Report}

2.1 Refractive Index of Reactive Atmosphere Processed (RAP) Potassium Chloride and Potassium Chloride Doped with Potassium Iodide

Marilyn J. Dodge and Irving H. Malitson

\subsubsection{Introduction}

It has been established that optical distortion can occur in laser windows subjected to high power laser radiations $[1-5]^{1}$. To predict the amount of distortion, it is necessary to know the refractive index, $n$, temperature coefficient of index, $\mathrm{dn} / \mathrm{dT}$, and the thermal-expansion and stress-optical coefficients of candidate laser window materials. An optical materials characterization program is [6] currently in progress at NBS to determine these pertinent optical properties. The refractometry laboratory at NBS is determining the index of refraction and $\mathrm{dn} / \mathrm{dT}$ of selected window materials over a limited temperature range.

Potassium chloride is one of the most promising candidates in the search for potential window and auxiliary optical component materials for use in high-power laser systems. It has useful transparency from about 0.2 to $20 \mu \mathrm{m}$ with $90 \%$ transmittance from 0.45 to $14 \mu \mathrm{m} \mathrm{[7].}$ Recent1y, ultra pure KC1 having very low absorption [8] has been developed and a specimen grown at Naval Research Laboratory by reactive atmosphere processing (RAP) was made available by Dr. Philip Kline for refractive index and temperature coefficient studies. KC1 doped with ions is also being considered for laser windows. A specimen of $\mathrm{KC} 1$ doped with $1.5 \%$ KI grown at Honeywell Corporation Research Center ${ }^{2}$ was supplied for this investigation by $\mathrm{Dr}$. E. Bernal. A sample of single crystal KCl grown by traditional techniques at Harshaw Chemical Corporation about 1966 has been studied by this laboratory and preliminary data were previously reported [9]. For comparison purposes with the results of this investigation on RAP and doped KC1 the final data of the earlier study are also presented.

\subsubsection{Experimenta1 Technique}

The specimens were in prismatic form and were measured by means of the minimum-deviation method using a precision spectrometer shown schematically in figure 1[10]. In the ultraviolet, visible and near infrared regions of the spectrum, the index was measured at known emission wavelengths of mercury, cadmium, zinc and helium. Beyond $2.0 \mu \mathrm{m}$ a globar was used for the radiant-energy source, and measurements were made

1. Figures in brackets indicate the literature references at the end of this paper.

2. The use of company and brand names in this paper are for identification purposes only and in no case does it imply recommendation or endorsement by the National Bureau of Standards and it does not imply that the materials used in this study are necessarily the best available. 
at known absorption bands of water vapor, carbon dioxide, polystyrene and 1,2-4 trichlorobenzene. A series of narrow-band interference filters was also used between 3.5 and $10.6 \mu \mathrm{m}$. A thermocouple with a cesium iodide window was used for the detector in the infrared and a photocell was used in the ultraviolet below .25 $\mu \mathrm{m}$. This spectrometer has a scale which can be read to within one second of arc. Therefore, the refractive index of good optical material can be measured within a few parts in $10^{-5}$ over a wide wavelength range.

The refractive index was determined from the ultraviolet to the infrared for al1 samples near $20^{\circ} \mathrm{C}$ and for the commercial and RAP specimens near $30^{\circ} \mathrm{C}$ and $34^{\circ} \mathrm{C}$ respectively. Each set of experimental data was fitted by a least square solution to a three-term Sellmeier-type dispersion equation [11] of the form

$$
n^{2}-1=\sum_{j=1}^{N} \frac{A_{j} \lambda^{2}}{\lambda^{2}-\lambda_{j}{ }^{2}} .
$$

The index of refraction is represented by $n, \lambda$ is the wavelength of interest, the $\lambda_{j}$ 's are the calculated wavelengths of maximum absorption and the $A_{j}^{\prime}$ 's are the calculated oscillator strengths corresponding to the absorption bands. Primary emphasis is given to procuring a matheematical fit of the measured data useful for interpolation. The $\lambda$ 's and the $A_{j}$ 's are not intended to have any physical significance and are influenced by the wavelength range covered by the experimental data.

\subsubsection{Index Data}

The constants calculated for each dispersion equation, the wavelength range covered by the experimental data, the number of experimental points, and the average absolute residual (the average difference between the experimental values and the calculated values) are given in table 1.

TABLE 1: CONSTANTS FOR DISPERSION EQUATIONS FOR KC1

\begin{tabular}{|c|c|c|c|c|c|}
\hline & Har & rshaw & & & KI-Doped \\
\hline & $19.40^{\circ} \mathrm{C}$ & $29.50^{\circ} \mathrm{C}$ & $20.20^{\circ} \mathrm{C}$ & $33.80^{\circ} \mathrm{C}$ & $19.90^{\circ} \mathrm{C}$ \\
\hline & 0.74783561 & 0.96002778 & 0.80902239 & 0.82044813 & 0.78085271 \\
\hline & 0.42626630 & 0.21344321 & 0.36511458 & 0.35248240 & 0.39493953 \\
\hline & 4.6867104 & 9.9867010 & 2.2323342 & 1.6784518 & 2.2662238 \\
\hline & 0.083633417 & 0.096438975 & 0.088281620 & 0.089075558 & 0.086111530 \\
\hline 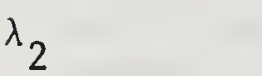 & 0.15389998 & 0.17244608 & 0.15737774 & 0.15835015 & 0.15600595 \\
\hline 3 & 95.063422 & 137.82107 & 65.870423 & 57.529058 & 66.360157 \\
\hline $\begin{array}{l}\text { No of } \\
\text { Wavelengths }\end{array}$ & 79 & 21 & 58 & 39 & 54 \\
\hline $\begin{array}{l}\text { Wavelength } \\
\text { Range }(\mu \mathrm{m})\end{array}$ & $0.22-14.4$ & $0.28-14.4$ & $0.25-15.5$ & $0.25-15.5$ & $0.25-15.5$ \\
\hline $\begin{array}{l}\text { verage } \\
\text { bsolute } \\
\text { esidual }\end{array}$ & 2.3 & 6.8 & 2.9 & 3.9 & 3.2 \\
\hline
\end{tabular}

of ipdex

$\times 10^{5}$ 


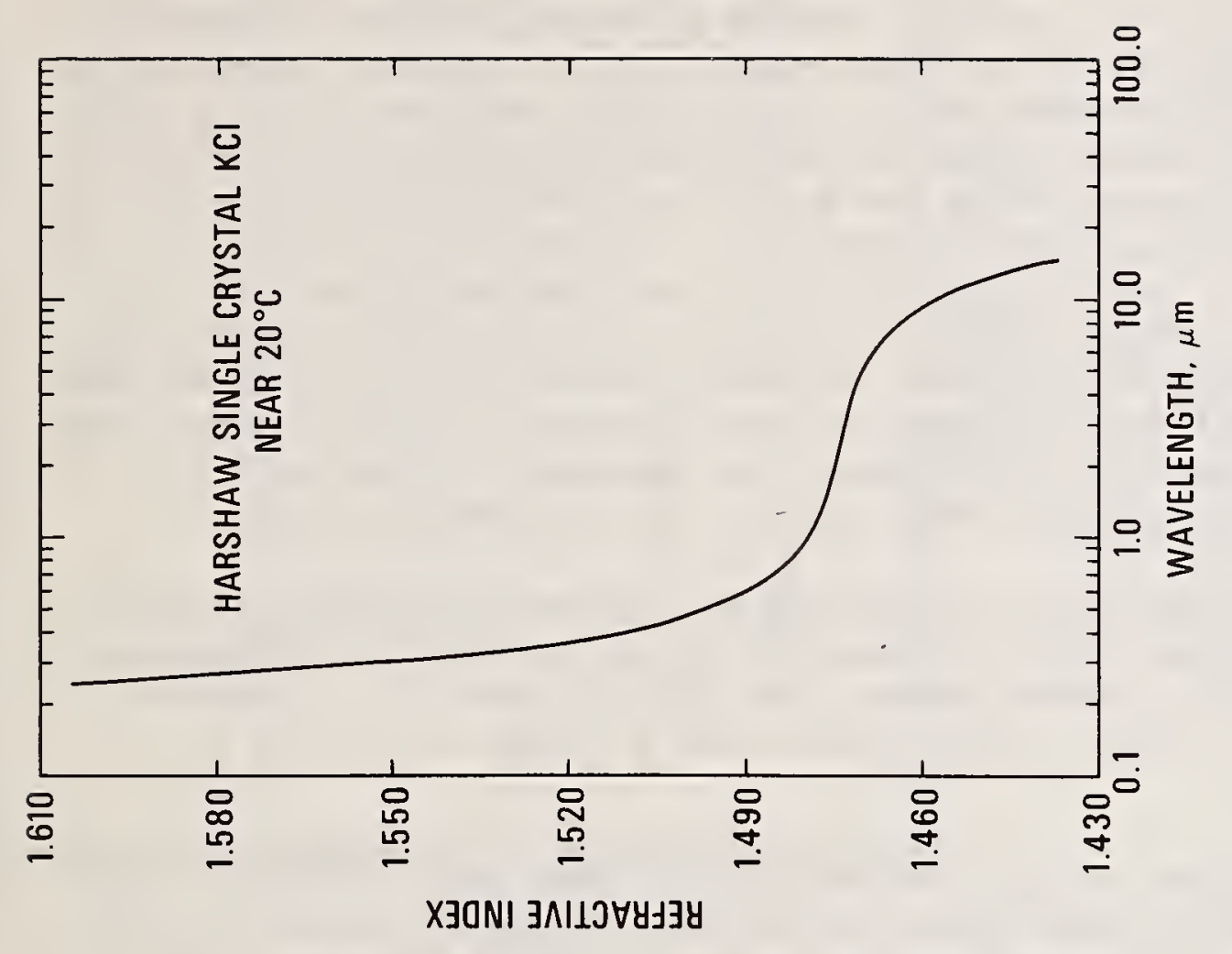

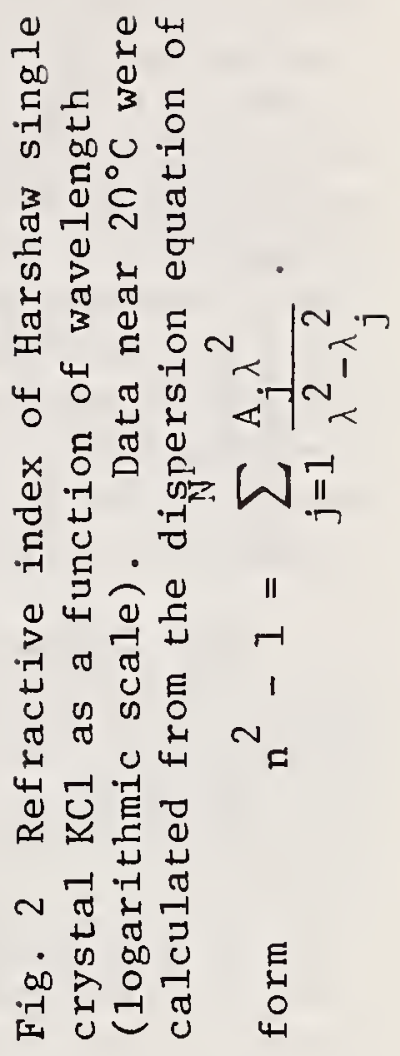

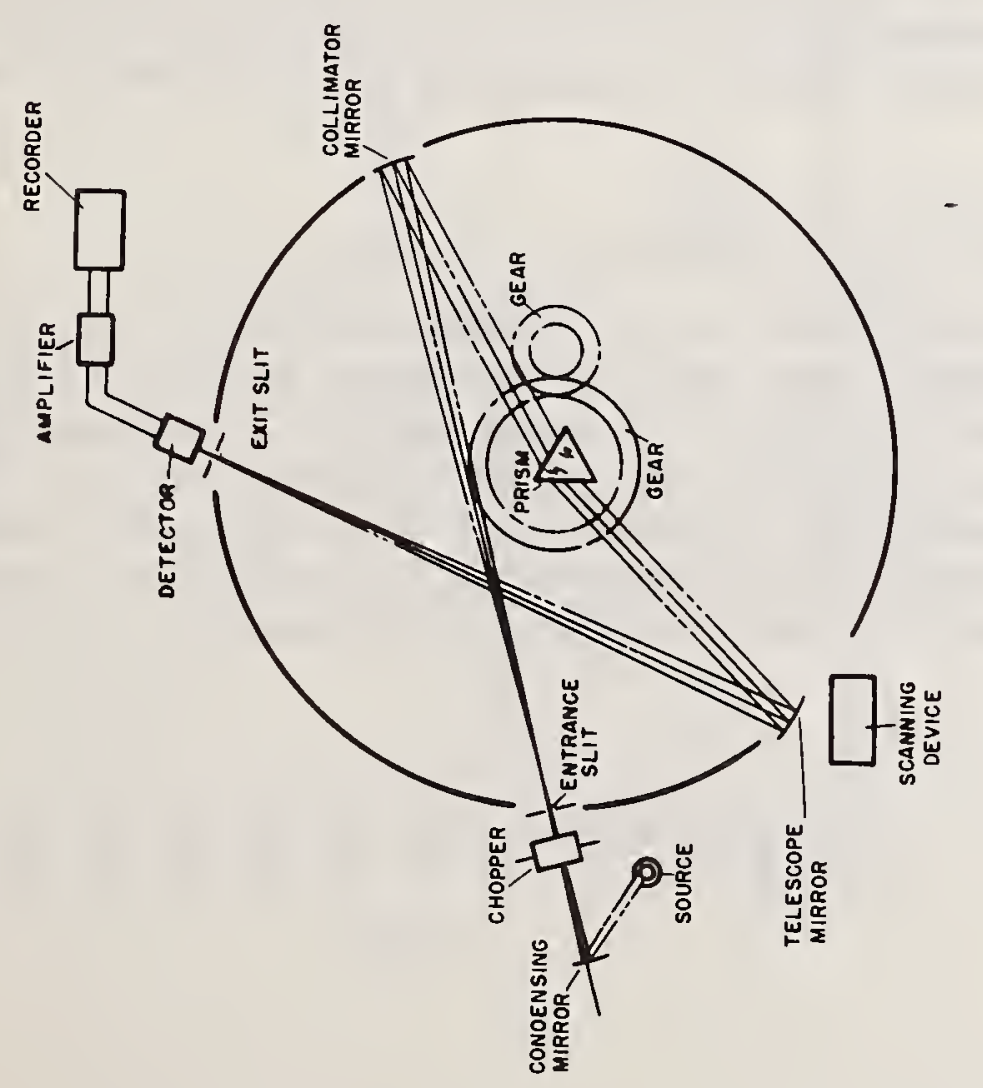

总点出

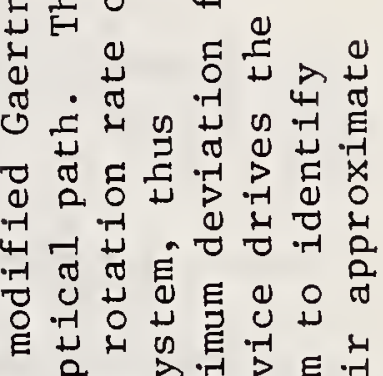

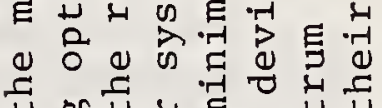

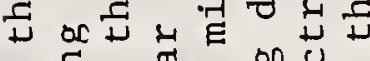

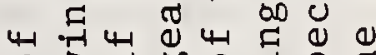

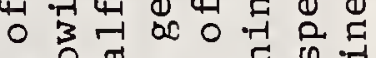

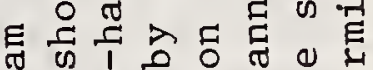
का

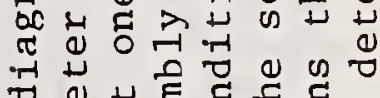

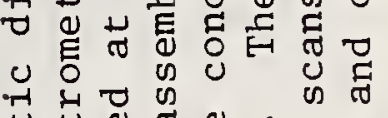

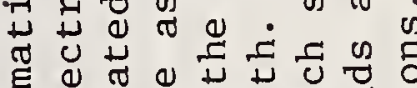
है

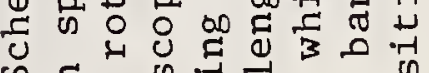
凹 -

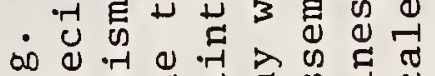

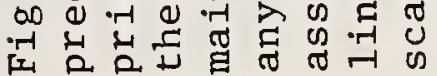


The stated average absolute residual shows the goodness of $\mathrm{fit}$ and is indicative of the accuracy of the experimental data. The largest residuals occur in regions where the largest uncertainties exist in wavelength identifications. Absorption spectra induced by atmospheric conditions superimposed on the absorption spectra being used for measurements, especially in the 5 to $8 \mu \mathrm{m}$ range, and broad, less well defined bands beyond $10 \mu \mathrm{m}$ are the primary sources of these errors. Because of the nature of the uncertainties their magnitude is not well known but an error of $0.5 \%$ at $10.0 \mu \mathrm{m}$ would result in an index residual of $18 \times 10^{-5}$. As $\mathrm{dn} / \mathrm{d} \lambda$ increases, a small error in wavelength assignment will result in larger index residuals. As a check on the individual Sellmeier solutions each set of data was divided into odd and even data points, that is, data points $1,3,5 \ldots$ and $2,4,6 \ldots$, and new solutions for each half were obtained. Their excellent agreement showed that the fitting procedure was not sensitive to the increased random error at the extreme wavelengths. A complete repetition of the experiment using the same and new KCl samples is needed to determine the components of variation related to materials and also other sources of systematic error.

The refractive index was calculated at regular wavelength intervals for each case using the fitted parameters given in table 1 . Figure 2 shows the index of the Harshaw sample near $20^{\circ} \mathrm{C}$ plotted as a function of the wavelength. The index values range from 1.64588 at $0.22 \mu \mathrm{m}$ to 1.43670 at $14.4 \mu \mathrm{m}$.

A graphical comparison of the refractive index near $20^{\circ} \mathrm{C}$ of the RAP and KI-doped samples is made with the Harshaw sample in figure 3 . The index of refraction of ${ }_{-5}$ the RAP sample differs from the Harshaw sample by approximately $+3 \times 10^{-5} \mathrm{frgm} 0.3$ to $9.6 \mu \mathrm{m}$. Below $0.3 \mu \mathrm{m}$ the difference rises sharp 1 y to $+19 \times 10^{-5}$ at $0.25 \mu \mathrm{m}$, and drops sharply beyond $9.6 \mu \mathrm{m}$ to $-68 \times 10^{-5}$ at $14.4 \mu \mathrm{m}$.

The index values of the KI-doped sample are higher than those of the Harshaw specimen by about $136 \times 10^{-5}$ at $0.25 \mu \mathrm{m}$, drops off to a $+60 \times 10^{-5}$ at $0.8 \mu \mathrm{m}$, remains fairly constant to $8.0 \mu \mathrm{m}$, then drops to $-13 \times 10^{-5}$ at $14.4 \mu \mathrm{m}$.

\subsubsection{Temperature Coefficient of Index}

The calculated values of index at two temperatures for the Harshaw and RAP KCl specimens were used to determine $\Delta \mathrm{n} / \Delta \mathrm{T}\left({ }^{\circ} \mathrm{C}\right)^{-1}$. The results are plotted as a function of wavelength for each specimen in figure 4. The solid lines represent the $\Delta \mathrm{n} / \Delta \mathrm{T}$ values calculated from the fitted index values using the parameters at the respective temperatures given in table 1 . The dashed lines indicate $\Delta \mathrm{n} / \Delta \mathrm{T}$ calculated from experimental values at specific wavelengths as indicated by the data points on the curves. 


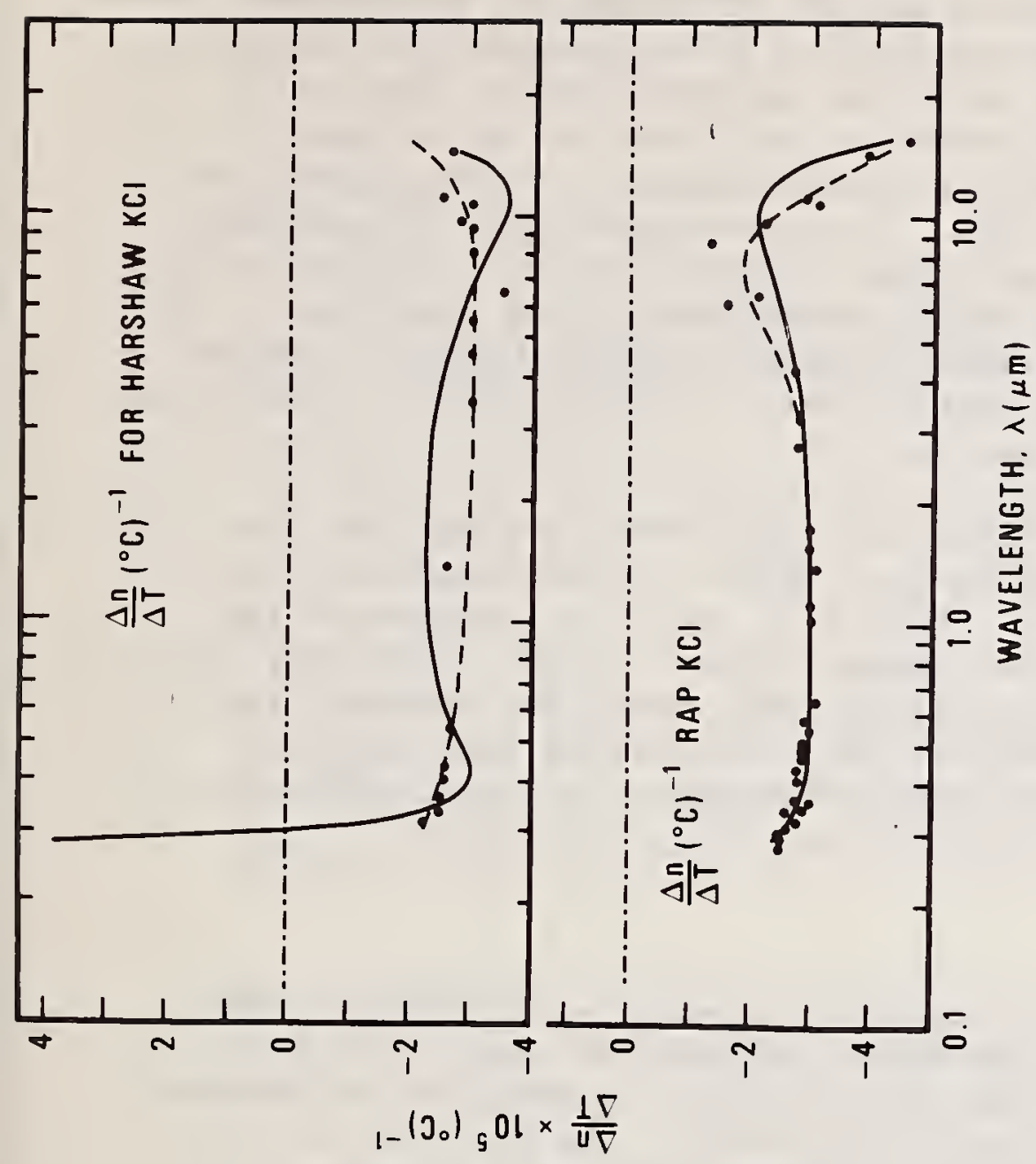

ฮู

ब

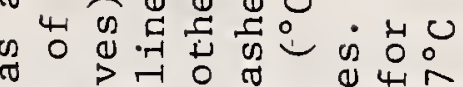
$x$ व

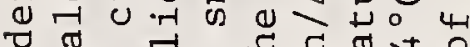
论

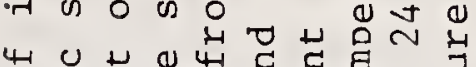

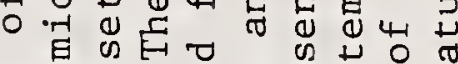

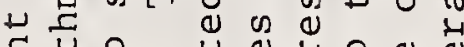

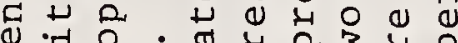
-

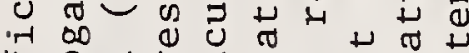
4

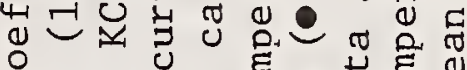
兘元

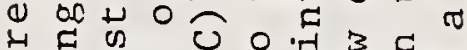

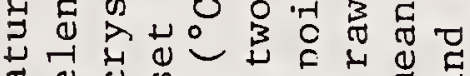

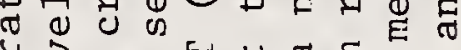

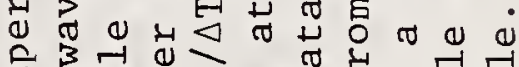

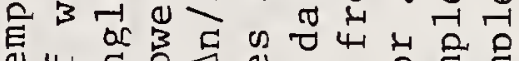
ब

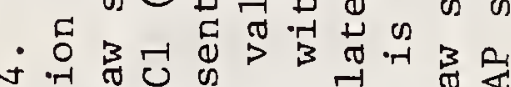

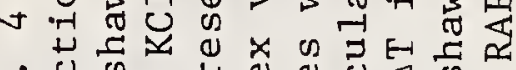

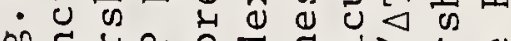

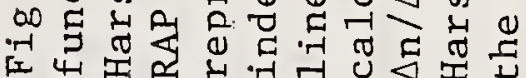

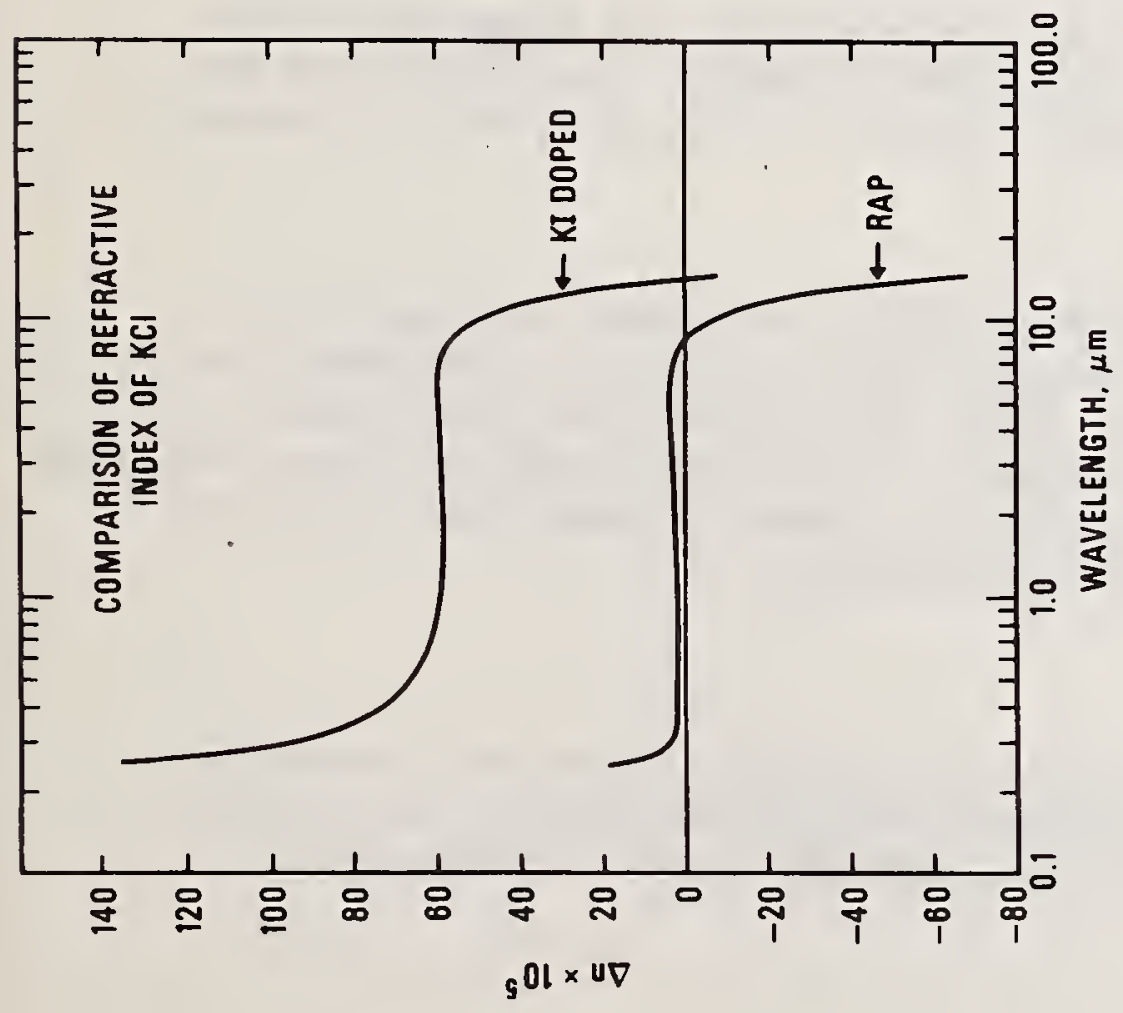

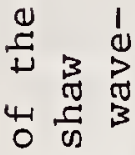

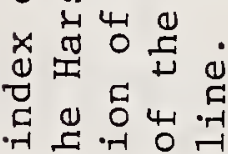

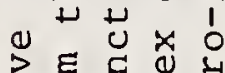
- $\rightarrow$ ह म (1)

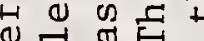
各合 D त

- $\rightarrow$ क 워 क तु त्र U \& \& क क ᄂ 0 U (1) 음ㄷㅁ 뭉

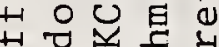
त 1 雨资 ¿ D ${ }^{\infty} 0^{\infty} 00$ त

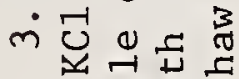
- o o o o of A E ह 당 एव 
The maximum differenge between the two curves for $\Delta \mathrm{n} / \Delta \mathrm{T}$ of Harshaw $\mathrm{KC} 1$ is eight parts in $10^{-}$between 10 and $14 \mu \mathrm{m}$, where the wavelength values corresponding to the experimental data have greater uncertainties. The curve representing the values based on the experimental data is of the same general shape as a curve based on published values by Paschen in 1908[12]. This curve also has the form which might be predicted from thermo-optic behavior of solids [13]. The negative $\Delta \mathrm{n} / \Delta \mathrm{T}$ indicates that a decrease in the density of the material is the primary factor effecting the change in index with an increase in temperature. The fact that $\Delta \mathrm{n} / \Delta \mathrm{T}$ becomes less negative near the UV and IR primary absorption edges indicates a shift of these edges towards longer wavelengths with increasing temperature.

The $\Delta \mathrm{n} / \Delta \mathrm{T}$ curves based on fitted and experimental values for the RAP KCl have essentially the same ${ }^{6}$ shape. Again the maximum difference between the two curves is $8 \times 10^{-6}$ between 12 and $14 \mu \mathrm{m}$. Although the rise in $\Delta \mathrm{n} / \Delta \mathrm{T}$ between $4 \mu \mathrm{m}$ and 9 or $10 \mu \mathrm{m}$ followed by the sharp drop in $\Delta \mathrm{n} / \Delta \mathrm{T}$ shown by both of these curves is not what would be expected, the very careful analysis of the data described earlier and the fact that the two curves both show the same trend makes these findings difficult to dispute at this time.

\section{1 .5 Conclusions}

This study indicates that $\mathrm{KCl}$ grown by traditional techniques and that grown by the new reactive atmosphere process have about the same index of refraction between 0.3 and $10.0 \mu \mathrm{m}$ with the absolute differences in index increasing on either side of this range. The addition of the $1.5 \%$ dopant of $\mathrm{KI}$, however, increased the index generally by about $60 \times 10^{-5}$ in the visible and infrared to about $9 \mu \mathrm{m}$ when it starts decreasing, and becomes about equal to the Harshaw sample at $14 \mu \mathrm{m}$.

Al1 of the data presented in this paper are for these particular samples and under the specific conditions stated. Caution should be used before applying any of these values to a sample of $\mathrm{KCl}$ of unknown origin.

Because of the lack of published data to support or dispute the $\Delta \mathrm{n} / \Delta \mathrm{T}$ curves which have been presented here, repeated measurements on the same samples are scheduled. Index and temperature coefficient determinations on other samples of $\mathrm{KCl}$ of the same types as those presented here might be indicated to determine if these findings are typical or peculiar to the samples in this investigation.

\section{1 .6 Acknowledgement}

The authors express their sincere appreciation to Mr. Joseph $\mathrm{M}$. Cameron, Chief, Office of Measurement Services at NBS for his careful analysis of the index and $\Delta \mathrm{n} / \Delta \mathrm{T}$ data and his helpful comments and suggestions. 


\subsubsection{References}

[1] M. Sparks, J. App1. Phys. 42, 5029 (1971).

[2] J. R. Jasperse and P. D. Gianino, J. App1. Phys. 43, 1686 (1972).

[3] B. Bendow, J. R. Jasperse, and P. D. Gianino, Opt. Commun. 5, 98 (1972).

[4] B. Bendow, P. D. Gianino, A. Hordvik, and L. H. Skolnik, Opt. Commun. 7, 219 (1973).

[5] B. Bendow and P. D. Gianino, Appl. Phys. 2 , 1 (1973).

[6] A. Feldman, I. Malitson, D. Horowitz, R. $\bar{M}$. Waxler and M. Dodge, Laser Induced Damage in Optical Materials: 1974, NBS Special Pub. 414, 141 (1974).

[7] Harshaw Optical Crystals, The Harshaw Chemical Co. (1967).

[8] Dr. Philip Kline, Naval Research Laboratory, private communication.

[9] See Reference 6

[10] W. S. Rodney and R. J. Spindler, J. Res. Nat. Bur. Stds. (U.S.), 51, 123 (1953).

[11] L. E. Sutton and O. N. Stavroudis, J. Opt. Soc. Am. 51, 901 (1961).

[12] A. Smakula, office of Technical Services; U.S. Dept. of Commerce (October 1952), p. 66 .

[13] S. Ramaseshan, K. Vedam, R. Krishnan, in Progress in Crystal Physics, Vol. I, edited by R. Krishnan (Interscience Publishers, New York, London, 1960), p. 139. 
2.2 Photoelastic Constants of Reactive Atmosphere Processed (RAP) Potassium Chloride and Potassium Chloride Doped With Potassium Iodide - Albert Feldman, Deane Horowitz and Roy M. Waxler

\section{2 .1 Introduction}

The measurement of piezo-optical constants of materials in the infrared is part of a program of optical materials characterization. The properties measured in this program are, refractive index, temperature coefficient of index, thermal expansion coefficient, photo-elastic constants, and elastic constants. These parameters are necessary for evaluating the performance of high-power infrared laser windows subjected to intense laser radiation. Absorption of a relatively small fraction of this radiation can produce temperature and stress gradients of sufficient magnitude to produce intolerable optical distortion and hence to render a window useless.1,2

In this paper we present the photoelastic constants of reactive atmosphere processed (RAP) $\mathrm{KCl}$ and $\mathrm{KCl}$ doped with $\mathrm{KI}$. We measured the constants at $10.6 \mu \mathrm{m}$ using a Soleil-Babinet type compensator and a modified Twyman-Green interferometer. The precision of measurement required in order to obtain reasonably precise values for the coefficients was $\sim .002$ of a fringe shift at $10.6 \mu \mathrm{m}$ because of the inability of the specimens to withstand large stresses. 3

\subsubsection{Discussion}

The definition of the piezo-optical coefficients has been discussed extensively in the literature and need not be discussed here. There are three independent coefficients, $q_{11}$, $q_{12}$, and $q_{44}$, for cubic materials of class $\mathrm{m} 3 \mathrm{~m}$ to which $\mathrm{KCl}$ belongs. The coefficients $\mathrm{q}_{44}$ and $\mathrm{q}=\mathrm{q}_{11}-\mathrm{q}_{12}$ describe stress-induced birefringence in a material, whereas $\mathrm{q}_{11}$ and $\mathrm{q}_{12}$ individually are needed to describe the absolute change of refractive index due to stress.

The stress-induced birefringence is measured most easily and with the greatest precision with a de senarmont compensator and we have successfully used this apparatus in the visible on the two types of $\mathrm{KCl} .5$ However, in the infrared at $10.6 \mathrm{~mm}$ this apparatus is not readily available; hence, we use a Babinet-Soleil type compensator. The experimental arrangement is shown in Figure 5. The variable wave plate (VWP) is a specimen of singlecrystal Ge in the form of a rectangular prism $12 \times 12 \times 36 \mathrm{~mm}$ with the [100] axis along the long dimension. The specimen is placed in a screw clamp stressing apparatus 6 and stress is applied along the [100] axis at an ang].e of $45^{\circ}$ with respect to the vertical in a plane perpendicular to the beam axis. The purpose of the VWP is to appropriately polarize the beam in order to maximize the intensity transmitted through the wire-grid polarizer, which is also oriented at $45^{\circ}$ with respect to the vertical in the plane perpendicular to the beam axis.

The compensator is the same as the VWP except that a calibrated precision stressing frame is used with the stress along the vertical. The stressing frame has been discussed in the literature. 7 The Ge specimen in the frame is calibrated by obtaining the shift of a specified number of fringes as a function of the applied force and by calculating the fringe shift per unit applied force $(\Delta \mathrm{N} / \Delta \mathrm{F}) \mathrm{Ge}$. 


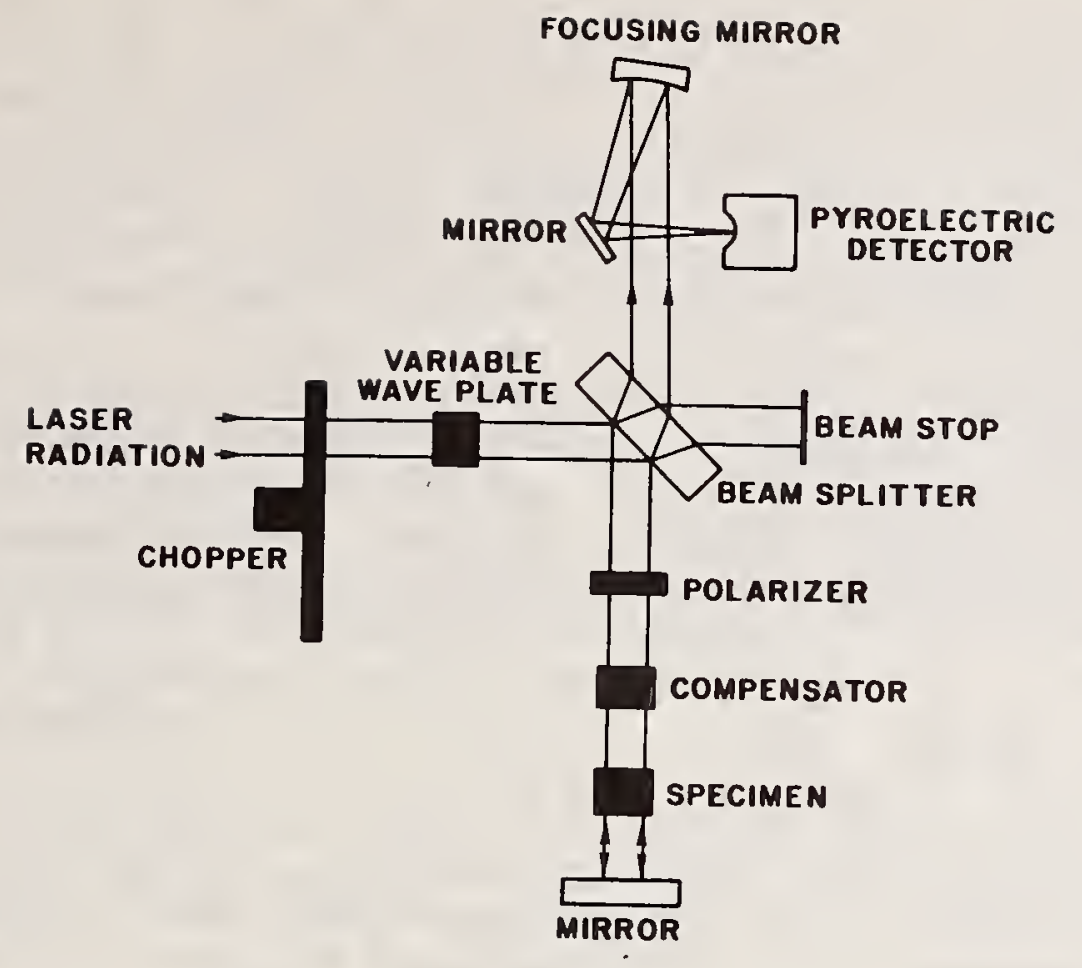

Figure 5. Apparatus for measuring stress-induced birefringence.

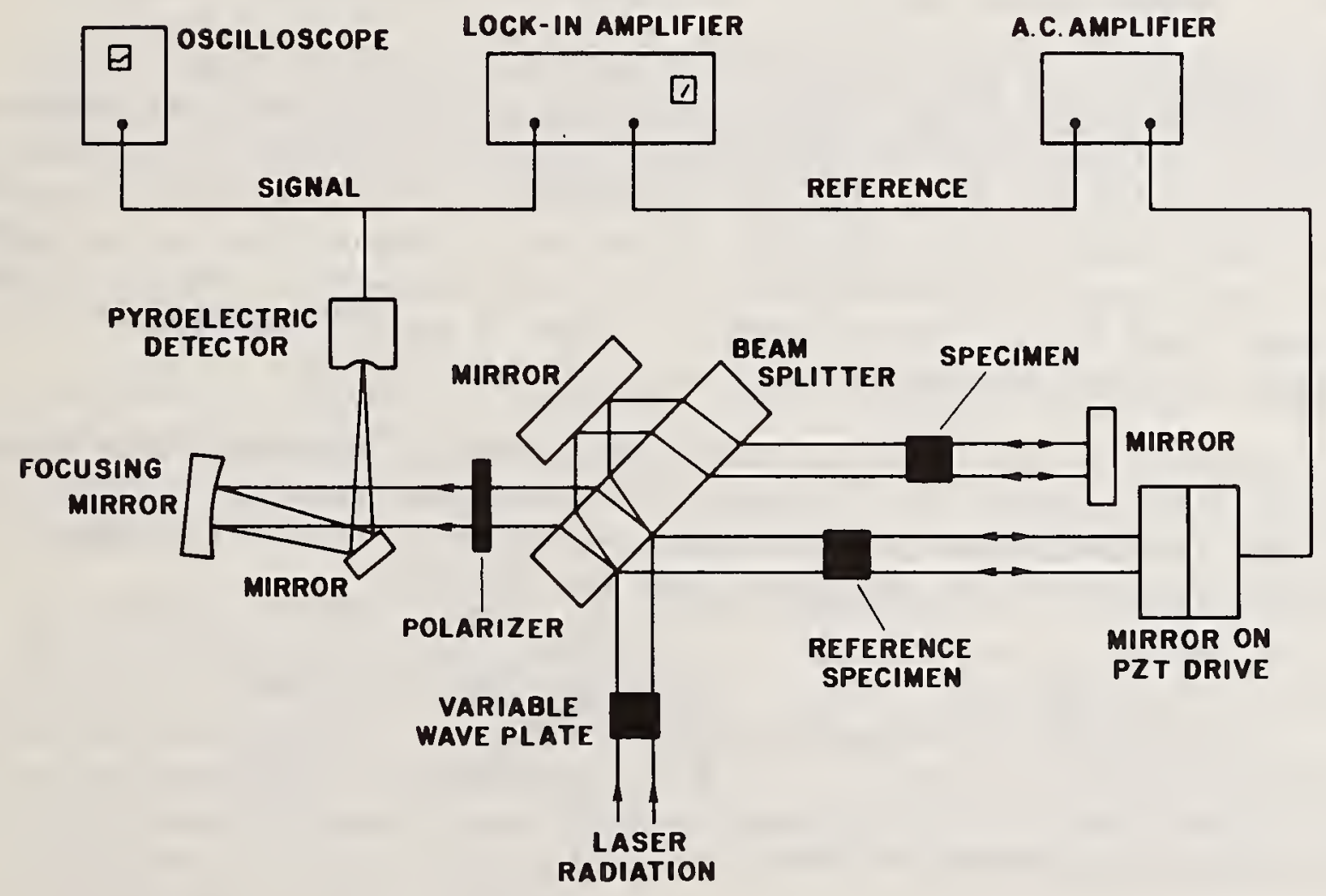

Figure 6. Apparatus for measuring absolute piezo-optic constants. 
The unknown specimen is placed in a similar calibrated precision stressing frame, with the stress applied along the vertical. The specimen has the same dimensions as the VWP and the compensator. The retardation in the specimen is measured as follows: Stress is applied to the compensator until a first order null is obtained, which occurs at an applied force of about $2700 \mathrm{~N}$ (600 lbs.). A small incremental stress is then applied to the specimen $\triangle \mathrm{F}_{\mathrm{KCl}}$ which produces a signal at the detector. The force on the compensator is then either increased or decreased by an amount $\Delta \mathrm{F}_{\mathrm{Ge}}$ until the system is returned to a null and the stress readings are recorded. This procedure is repeated until what we consider to be the maximum allowable force is applied to the specimen. For the RAP $\mathrm{KCl}$ this force is $178 \mathrm{~N}$ (40 lbs.) yielding a stress of 11 bars, and for the KI doped KCl this force is $356 \mathrm{~N}$ (80 lbs.) yielding a stress of 21 bars. With these data and with the Ge calibration, we obtain the stress birefringence constants for the $\mathrm{KCl}$ from the equation

$$
q=\frac{\lambda w}{n^{3}}\left(\frac{\Delta N}{\Delta F}\right) \frac{\Delta F_{G e}}{\mathrm{Ge}_{\mathrm{KCl}}} \quad \begin{cases}q=q_{11}-q_{12} & \text { for [100] stress } \\ q=q_{44} & \text { for [11l] stress }\end{cases}
$$

where $\lambda$ is the wavelength, $w$ is the specimen width, and $\mathrm{n}$ is the specimen refractive index. Equation (1) is valid because $\Delta \mathrm{F}_{\mathrm{Ge}}$ varies linearly with $\Delta \mathrm{F}_{\mathrm{KCl}}$.

The method for measuring the absolute piezo-optic constants $\mathrm{q}_{11}$ and $\mathrm{q}_{12}$ with a modified Twyman-Green interferometer has been described in earlier publications ${ }^{8}, 9$; consequently it will not be described here. slight modifications have been made to the apparatus, however, and these are shown in Figure 6 which is a schematic of the apparatus. A VWP has been added to permit orientation of the radiation polarization vector either parallel or perpendicular to the stress axis of the specimen. A wire-grid polarizer has been added to correct for errors in the setting of the VWP and to insure that radiation of the proper polarization reaches the detector. In addition, focusing optics have been added to the detection system to permit detection of smaller radiation power. The use of lower power diminishes the possibility of heating of optical elements due to residual absorption which could produce drift in the interferometer. Thus, although the $\mathrm{CO}_{2}$ laser used has an output power of about 4 watts, measurements are usually made with an attenuated power of less than $500 \mathrm{~mW}$.

The fringe shift per unit applied force $\Delta \mathrm{N} / \Delta \mathrm{F}$ is measured on a specimen subjected to [001] stress for the radiation polarized parallel to the stress axis and then for radiation polarized perpendicular to the stress axis. The piezo-optical constants are obtained from the equation

$$
\frac{\lambda w}{2} \frac{\Delta N}{\Delta F}=\frac{n^{3}}{2} q-n_{12}\left\{\begin{array}{l}
q=q_{11} \text { for } \vec{e}||[001] \\
q=q_{12} \text { for } \vec{e} \perp[001]
\end{array}\right.
$$

where $\vec{e}$ is the polarization vector.

\section{2 .3 Results}

The piezo-optical constants of pure and doped single-crystal specimens of $\mathrm{KCl}$ were measured at $10.6 \mu \mathrm{m}$. The four specimens are listed in Table 2 together with their crystallographic orientations. The constants we obtained are listed at the bottom of Table 3 together with earlier reported data in the 
visible. In computing $\mathrm{q}_{11}$ and $\mathrm{q}_{12}$ we used a value of $\mathrm{s}_{12}=-3.63 \times 10^{-12} \mathrm{~m}^{2} / \mathrm{N}$ which is an average of many values presented in the literature.10 Earlier we had reported preliminary stress-optical constant values at $10.6 \mu \mathrm{m}^{5}$; however, the data we present here have a greater precision. The errors given represent the standard deviation of many measurements and the size of the errors corresponds to a fringe shift of approximately .002 $\lambda$ at $10.6 \mu \mathrm{m}$. The values for $q_{11}-q_{12}$ that we present are data obtained independently from $q_{11}$ and $q_{12}$.

An examination of Table 3 shows that earlier workers did not report values for the coefficients $q_{11}$ and $q_{12}$, but rather values for $p_{11}$ and $\mathrm{p}_{12}$. They do report values for $\mathrm{q}_{11}-{ }^{\mathrm{l}_{1}} \mathrm{q}_{12}$ and $\mathrm{q}_{44}$. A comparison of our data with the earlier work suggests that some dispersion exists in $q_{4}$ in going from the visible to $10.6 \mu \mathrm{m}$, whereas the dispersion in $q_{11} \underline{4}^{4} q_{12}$ is negligible within the experimental error. Our data also indicate that, within experimental error, the dispersions in $\mathrm{q}_{11}$ and $\mathrm{q}_{12}$ individually are also negligible.

At the lower part of Table 4 we list the elasto-optic constants we have calculated from the piezo-optical constants using the formula

$$
p_{i k}=\sum_{j} q_{i j} s_{j k}
$$

where $s_{11}=26.9 \times 10^{-12} \mathrm{~m}^{2} / \mathrm{N}$ and $s_{44}=150.7 \times 10^{-12} \mathrm{~m}^{2} / \mathrm{N}$. The elastic compliance components are an average of values from a compilation ${ }^{10}$ which contains a large variation in values. A comparison of our values with values of other workers indicates agreement for some values, and disagreement for others. There is little dispersion in $\mathrm{p}_{11}$ and $\mathrm{p}_{12}$, but some dispersion in $\mathrm{P}_{44^{\circ}}$

In the calculations we have used the same elastic constants for both the doped and the RAP KCl because of lack of values for the undoped. On this basis the measurements and calculations indicate that, within experimental error, the piezo-optical constants of the two types of material are the same.

\subsubsection{Acknowledgement}

We thank E. Bernal of Honeywell and P. Klein of the U. S. Naval Research Laboratory for supplying materials for the specimens.

\subsubsection{References}

1. M. Sparks, J. Appl. Phys. 42, 5029 (1971).

2. J. R. Jasperse and P. D. Gianino, J. Appl. Phys. 43, 1686 (1972); B. Bendow and P. D. Gianino, Appl. Phys. 2, 1 (1973); B. Bendow, P. D. Gianino, A. Hordvik, and L. H. Skolnik, Optics Commun. 7, 219 (1973).

3. W. W. Wilkening, J. Friedman, and C. A. Pitha, in Third Conference on High Power Infrared Laser Window Materials, 1973, ARCRL-TR-74-0085-I.

4. J. F. Nye, Physical Properties of Crystals (Oxford University Press, London, 1957), pp. 243-254.

5. A. Feldman, D. Horowitz, and R. M. Waxler, in Laser Induced Damage in Optical Materials: 1975, to be published as a Special NBS Publication.

6. A. Feldman, D. Horowitz, and R. M. Waxler, in Third Conference on High Power Infrared Laser Window Materials, 1973, AFCRL-TR-74-0085-I, p. 403.

7. A. Feldman and W. J. McKean, Rev. Sci. Instrum. 46, 1588 (1975). 
8. A. Feldman, I. H. Malitson, D. Horowitz, R. M. Waxler and M. Dodge, in Proceedings of the Fourth Annual Conference on Infrared Laser Window Materials, 1974, p. 117.

9. A. Feldman, R. M. Waxler, and D. Horowitz, in Optical Properties of Highly Transparent Solids, edited by S. S. Mitra and B. Bendow (Plenum Publishing Corp., New York, 1975), p. 517.

10. R. V. G. Sundara Rao, K. Vedam, and R. S. Krishnan, in Progress in Crystal Physics, Vol. I, edited by R. S. Krishnan (Interscience Publishers, New York, London, 1960), p. 89. 
Table 2. Specimen Orientations

\begin{tabular}{lccc}
\hline Specimen & \multicolumn{2}{c}{ Orientation } & Constants Measured \\
\hline $1-\operatorname{RAP} \mathrm{KCl}$ & Stress & Propagation & \\
$2-\operatorname{RAP} \mathrm{KCl}$ & {$[001]$} & {$[110]$} & $\mathrm{q}_{11^{\prime}} \mathrm{q}_{12^{\prime}} \mathrm{q}_{11}-\mathrm{q}_{12}$ \\
$3-$ Doped KCl(18 KI nom) & {$[001]$} & {$[110]$} & $\mathrm{q}_{44}$ \\
$4-$ Doped KCl (1\% KI nom) & {$[110]$} & {$[001]$} & $\mathrm{q}_{11^{\prime}} \mathrm{q}_{12}, \mathrm{q}_{11}-\mathrm{q}_{12}$ \\
\hline
\end{tabular}

Table 3. Piezo-Optic Constants of $\mathrm{KCl}\left(10^{-12} \mathrm{~m}^{2} / \mathrm{N}\right)$

\begin{tabular}{|c|c|c|c|c|c|c|}
\hline & $\lambda(\mu \mathrm{m})$ & $q_{11}$ & $q_{12}$ & $q_{44}$ & $q_{11}-q_{12}$ & Ref. \\
\hline & .589 & & & -4.22 & 1.67 & a \\
\hline & .589 & & & -4.42 & 1.66 & $b$ \\
\hline & .589 & & & -4.94 & 1.47 & c \\
\hline & .480 & & & & 1.42 & $d$ \\
\hline & .589 & & & $-4 \cdot 74$ & 1.57 & e \\
\hline & .633 & & & & 1.81 & $f$ \\
\hline & .633 & $4.6 \pm .2$ & $2.7 \pm .8$ & $-3.9 \pm .8$ & $1.7 \pm .4$ & $g$ \\
\hline & .644 & & & $-4.4 \pm .2$ & $1.9 \pm .4$ & $g$ \\
\hline * & .633 & $4.6 \pm .2$ & $2.8 \pm .2$ & $-4.6 \pm .2$ & $1.9 \pm .2$ & $g$ \\
\hline * & .644 & & & $-4.7 \pm .2$ & $1.9 \pm .1$ & $g$ \\
\hline & 10.6 & & & & 2.0 & $\mathrm{~h}$ \\
\hline & 10.6 & & & -2.62 & & \\
\hline & 10.6 & $4.3 \pm .3$ & $2.8 \pm .3$ & $-3.4 \pm .4$ & $1.8 \pm .4$ & \\
\hline * & 10.6 & $4.2 \pm .2$ & $2.5 \pm .2$ & $-3.6 \pm .3$ & $1.8 \pm .2$ & \\
\hline
\end{tabular}

*Nominally doped with $18 \mathrm{KI}$

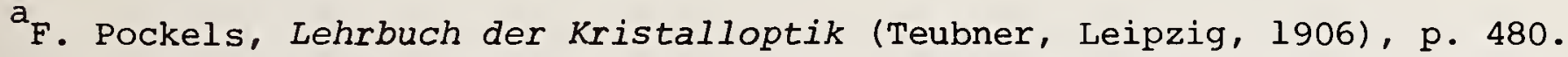

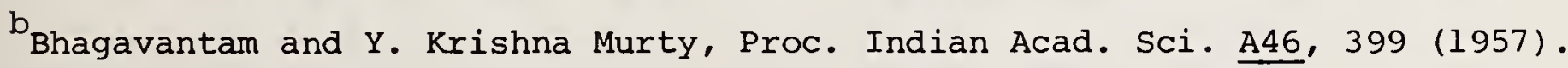

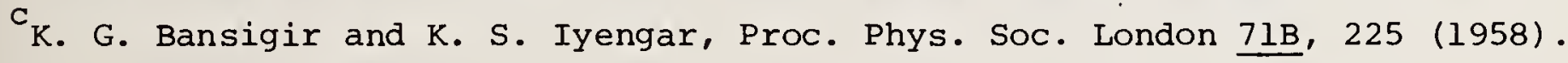

$d_{R}$. Srinivasan, Zeit. f. Physik 155, 281 (1959).

${ }^{\text {e }}$. V. Krishna Rao and V. G. Krishna Murty, Proc. Indian Acad. Sci. 64, 24 (1966). f Reference 3 .

$9_{\text {Reference } 5 .}$

hC. S. Chen, J. P. Szcznesniak, and J. C. Corelli, J. Appl. Phys. 46, 303 (1975).

${ }^{i}$ C. A. Pitha and J. D. Friedman, in Proceedings of the Fourth Annual Conference

on Infrared Laser Window Materials, 1974, compiled by C. R. Andrews and

C. L. Strecker. 
Table 4. Elasto-Optic Constants of $\mathrm{KCl}$

\begin{tabular}{rlllll}
\hline$\lambda(\mu \mathrm{m})$ & $p_{11}$ & $p_{12}$ & $p_{44}$ & $p_{12} / p_{11}$ & Ref. \\
\hline .589 & & & -0.0276 & & $\mathrm{a}$ \\
.589 & 0.215 & 0.159 & -0.024 & -0.74 & $\mathrm{~b}$ \\
.589 & 0.246 & 0.192 & -0.0298 & -0.78 & $\mathrm{c}$ \\
.633 & 0.21 & 0.15 & -0.026 & -0.70 & \\
.644 & 0.21 & 0.15 & -0.029 & & \\
.633 & & & -0.031 & & \\
.644 & 0.20 & 0.15 & -0.031 & & \\
10.6 & 0.19 & 0.14 & -0.023 & -0.76 &
\end{tabular}

* Nominally doped with $1 \% \mathrm{KI}$

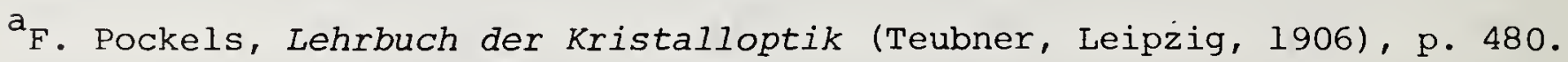

$\mathrm{b}_{\mathrm{K}}$. S. Iyengar, Nature 176, 1119 (1955).

$C_{K}$. V. Krishna Rao and V. G. Krishna Murty, Proc. Indian Acad. Sci. 64 24 (1966). 
3. Appendix

Specimen Specifications for Photoelasticity, dn/dT, Thermal Expansion, and Refractive Index Measurements. 
I. Photoelasticity Specimens

A. Specifications

1. Dimensions - Rectangular prism $1 / 2 " \times 1 / 2 " \times 1-1 / 2 "$ $(12 \times 12 \times 36 \mathrm{~mm})$

2. Polish two opposite $1 / 2 " \times 1-1 / 2 "(12 \times 36 \mathrm{~mm})$ Eaces.

a. Flatness - One (1) fringe $0.6328 \mu \mathrm{m}$ radiation when viewed against an optical flat across $90 \%$ of the central aperture area.

b. Parallelism* - Six (6) fringes of $0.6328 \mu$ m radiation when viewing Fizeau interference between both polished faces.

* Alternate parallelism specification: wedge angle between polished faces to be $25 \pm 5$ minutes:

3. Grind all other surfaces so that the angles between all adjacent surfaces to be $90^{\circ} \pm 1 \mathrm{~min}$. of area. No noticeable wedges, ridges or bumps shall be seen when testing angles with a precision machinist's knife-edge square. (In a wedged specimen this specification will hold for one polished face and the four ground surfaces.)

4. For single crystal specimens, orient the axes of the specimen along specified crystallographic axes to within one-half degree $\left(1 / 2^{\circ}\right)$.

5. Use grinding and polishing techniques that minimize adding strain to the specimen.

6. Polish faces to be perpendicular to the growth or deposition direction, if one exists and if compatible with above specifications.

\section{B. Specimens Required}

1. Amorphous or polycrystalline specimens - supply one parallel and one wedged.)

2. Cubic material specimens - supply one parallel and one wedged for each crystallographic orientation:

a. Long axis along [100]; other faces arbitrary.

b. Long axis along [111]; other faces arbitrary. If not available then an alternate form would be long axis along [110] and short axes along [110] and [001] with the [001] faces polished. 
3. Other crystal classes - contact us for required specimen orientations.

4. If possible supply duplicates of above specimens. 
II. Specimens for $\mathrm{dn} / \mathrm{dT}$ and Thermal Expansion $/$

A. Specifications

1. Dimensions - Plate $1 / 2$ " dia. $\times 1 / 4$ " to $1 / 2 "$ thick.

(12 $\mathrm{mm}$ dia. $x 6$ to $12 \mathrm{~mm}$ thick).

(Plate may be nominally $1 / 2$ " square

$\mathrm{x} 1 / 4$ " to $1 / 2$ " thick.)

2. Polish flat surfaces.

a. Flatness - One (I) fringe $0.6328 \mu \mathrm{m}$ radiation when viewed against an optical flat across $90 \%$ of the central aperture area.

b. Parallelism - Three (3) fringes of $0.6328 \mu \mathrm{m}$ radiation in a circular pattern when viewing Fizeau interference between both polished faces.

3. Polished faces to be perpendicular to the growth or deposition direction if one exists.

B. Specimens Required for $\mathrm{dn} / \mathrm{dm}$

1. Cubic*, polycrystalline, and amorphous materials - supply two specimens.

* Cubic specimens require no particular crystallographic orientation.

2. Other crystal classes - contact us for required specimen orientations.

C. Specimens for Thermal Expansion - Identical with dn/dT specimens. Two are required which may be prepared simultaneously with $\mathrm{dn} / \mathrm{dT}$ specimens. 
III. Refractive Index Specimens

A. Specifications

1. Triangular prism with two polished rectangular faces approximately $1^{\prime \prime}(2.5 \mathrm{~cm})$ square.

2. The angle between the two polished faces, $\theta$, to be given by the formula

$$
\theta=2 \sin ^{-1} \frac{.866}{n}
$$

within one (1) degree, where $\mathrm{n}$ is the maximum nominal index value, but $\theta$ is not to exceed $70^{\circ}$.

3. Polish the faces flat to $1 / 8$ wave $0.633 \mu \mathrm{m}$ light if possible.

B. Specimens Required

1. Cubic*, polycrystalline and amorphous material - supply one specimen.

* Cubic specimens require no particular crystallographic orientation.

2. Contact us for specimen requirements for non-cubic crystals.

3. As a test for homogeneity, supply specimens from different portions of a batch or from different batches. 
NOS. IIAA (REV. 7.73)

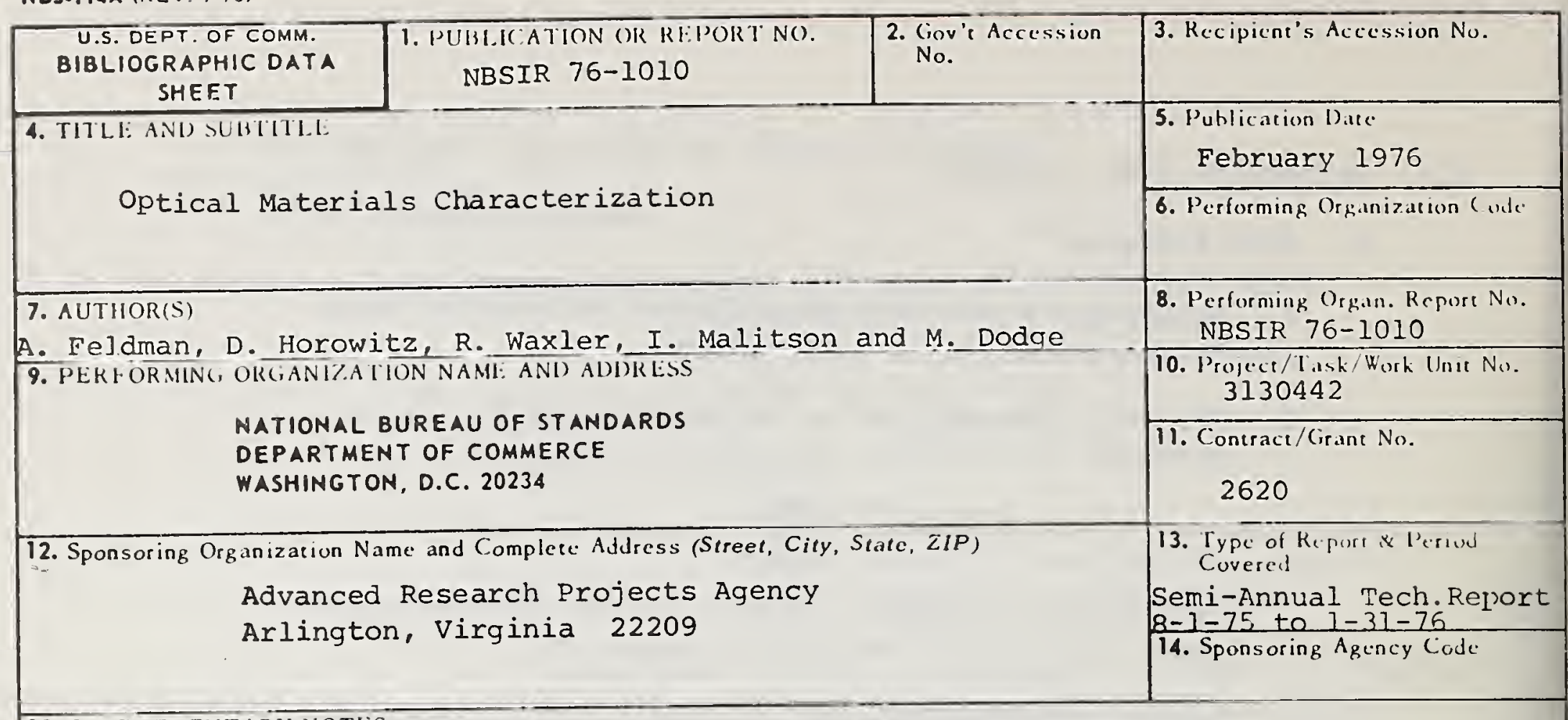

\section{SUPPLEMENTARY NOTES}

16. ABSTRACT (A 200-word or less factual summary of most significant information. If document includes a significant bibliography or literature survey, mention it here.)

Refractive index and the photoelastic constants have been measured on specimens of reactive atmosphere processed (RAP) $\mathrm{KCl}$ and $\mathrm{KCl}$ nominally doped with $1 \% \mathrm{KI}$. The refractive indices were measured by the minimum deviation method in the wavelength range $0.25 \mu \mathrm{m}$ to $15.5 \mu \mathrm{m}$. Measurements were made near $20^{\circ} \mathrm{C}$ and near $34^{\circ} \mathrm{C}$ on the RAP specimen and near $20{ }^{\circ} \mathrm{C}$ on the doped specimen. Each set of experimental data was fitted to a three term Sellmeier-type dispersion equation. The temperature coefficient of index was then computed for the RAP $\mathrm{KCl}$. The data for the different types of $\mathrm{KCl}$ were compared to eac other and to earlier reported data on commercial $\mathrm{KCl}$. The piezo-optical constants. $\mathrm{q}_{1 \mathrm{l}^{\prime}}$ $q_{12}$ and $q_{44}$ and the elasto-optical constants $p_{11}, p_{12}$ and $p_{44}$ were obtained at $10.6^{\prime} \mu m$ for the RAP and doped $\mathrm{KCl}$. The measurements required the use of a modified TwymanGreen interferometer capable of measuring fringe shifts $\sim .002$ of a wave. Within experimental error the coefficients of the two materials agree. Negligible dispersion was found for $q_{11}, q_{12}, p_{11}$ and $p_{12}$ between the visible and $10.6 \mu \mathrm{m}$ while a small dispersion was found for $\mathrm{q}_{44}$ and $\mathrm{p}_{44^{\circ}}$

17. KEY W'ORDS (six to twelve entries; alphabetical order; capitalize only the first letter of the first key word unless a proper name; separated by semicolons) Birefringence; elastooptic constants; infrared-laser window materials; interferometry; $\mathrm{KCl}$; photoelasticity; piezo-optic constants; refractive index; stress-optical constants; thermal coefficient of refractive index.

\section{AVAILABILITY \\ $\bar{X}$ Unlimited}

ए For Official Distribution. Do Not Release to NTIS

[ Order From Sup, of Doc., U.S. Government Prineing Office Washington, D.C. 20402, S1) (.at. No. (.13

X Order From National Technical Information Service (NTIS) Springfield, Virginia 22151

\begin{tabular}{|l|c|}
\hline $\begin{array}{l}\text { 19. SECURITY CI.ASS } \\
\text { (THIS REPURT) }\end{array}$ & 21. NO. OF PAGES \\
UNCL ASSIFIF: & 20 \\
\hline $\begin{array}{l}\text { 20. SI:CURITY ( I.ASS } \\
\text { (THIS PAGE) } \\
\text { UNCLASSIFII:I) }\end{array}$ & $\begin{array}{l}22 . \text { Price } \\
\$ 4.00\end{array}$ \\
\hline
\end{tabular}

